\title{
Adrenomedullin and adrenotensin regulate collagen synthesis and proliferation in pulmonary arterial smooth muscle cells
}

\author{
W. $\mathrm{Li}^{1 *}$, Q.Y. Kong ${ }^{2 *}$, C.F. Zhao ${ }^{2}$, F. Zhao ${ }^{3}$, F.H. Li ${ }^{2}$, W. Xia ${ }^{2}$, R. Wang ${ }^{4}$, Y.M. Hu ${ }^{1}$ and M. Hua ${ }^{5}$ \\ ${ }^{1}$ School of Control Science and Engineering, Biomedical Engineering Institute, Shandong University, Jinan, Shandong, China \\ ${ }^{2}$ Department of Pediatrics, Qilu Hospital, Shandong University, Jinan, Shandong, China \\ ${ }^{3}$ Department of Medicine, Weill Medical College of Cornell University, New York, NY, USA \\ ${ }^{4}$ Key Laboratory of Cardiovascular Remodeling and Function Research, Qilu Hospital, \\ Shandong University, Jinan, Shandong, China \\ ${ }^{5}$ Shandong Institute of Scientific and Technical Information, Jinan, Shandong, China
}

\begin{abstract}
To understand the pathophysiological mechanisms of pulmonary arterial smooth muscle cell (PASMC) proliferation and extracellular-matrix accumulation in the development of pulmonary hypertension and remodeling, this study determined the effects of different doses of adrenomedullin (ADM) and adrenotensin (ADT) on PASMC proliferation and collagen synthesis. The objective was to investigate whether extracellular signal-regulated kinase (ERK1/2) signaling was involved in ADM- and ADT-stimulated proliferation of PASMCs in 4-week-old male Wistar rats (body weight: 100-150 g, $n=10$ ). The proliferation of PASMCs was examined by 5-bromo-2-deoxyuridine incorporation. A cell growth curve was generated by the Cell Counting Kit-8 method. Expression of collagen I, collagen III, and phosphorylated ERK1/2 (p-ERK1/2) was evaluated by immunofluorescence. The effects of different concentrations of ADM and ADT on collagen I, collagen III, and p-ERK1/2 protein expression were determined by immunoblotting. We also investigated the effect of PD98059 inhibition on the expression of $p-E R K 1 / 2$ protein by immunoblotting. ADM dose-dependently decreased cell proliferation, whereas ADT dosedependently increased it; and ADM and ADT inhibited each other with respect to their effects on the proliferation of PASMCs. Consistent with these results, the expression of collagen I, collagen III, and p-ERK1/2 in rat PASMCs decreased after exposure to ADM but was upregulated after exposure to ADT. PD98059 significantly inhibited the downregulation by ADM and the upregulation by ADT of p-ERK1/2 expression. We conclude that ADM inhibited, and ADT stimulated, ERK1/2 signaling in rat PASMCs to regulate cell proliferation and collagen expression.
\end{abstract}

Key words: Adrenomedullin; Adrenotensin; Pulmonary arterial smooth muscle cell; Extracellular signal-regulated kinase-1; Collagen

\section{Introduction}

Increased pulmonary blood vessel thickness and stenosis are important pathophysiological components of pulmonary vascular remodeling (1-3). Pulmonary artery smooth muscle cell (PASMC) hypertrophy and hyperplasia, along with the accumulation of collagen and other extracellular-matrix components in the vascular wall, are major contributors to vascular remodeling.
Adrenomedullin (ADM) is a vasoactive polypeptide. Proadrenomedullin (proADM), the precursor to ADM, is cleaved by an endogenous peptidase, peptidylhydroxyglycine $\alpha$-amidating lyase, into four different active peptides, each of which has a distinct distribution and function (4,5). Among them, ADM and adrenotensin (ADT) are distributed throughout the vascular smooth

Correspondence: C.F. Zhao, Department of Pediatrics, Qilu Hospital, Shandong University, Jinan, Shandong 250012, China. Fax: +86-531-8692-7544. E-mail: zhaocuifen@sdu.edu.cn

${ }^{*}$ These authors contributed equally to this study.

Received April 18, 2013. Accepted July 29, 2013. First published online December 2, 2013. 
muscle cell layer, whereas proADM N-terminal 20 peptide (PAMP) is found within the tunica adventitia. ADM stimulates blood vessel dilation and inhibits smooth muscle cell proliferation and migration $(6,7)$. ADM activates the potassium channel in smooth muscle cells to enable cellular hyperpolarization (8). Through binding to the CGRP1 receptor, ADM further elevates cAMP levels in vascular smooth muscle cells and expands blood vessel diameter.

ADT is a vasoconstrictive agent that elevates blood pressure and increases the proliferation and migration of vascular smooth muscle cells (9). The mitogen-activated protein kinase (MAPK) intracellular signaling pathway modulates cell proliferation and is induced by a diverse collection of stimuli (10-12).

We have previously explored the distribution of SAPK/ JNK, P38, and ERK1/2 in the lungs in a pulmonary hypertension rat model. We found that ERK1/2 pathway activation was the most robustly stimulated. In addition, vascular smooth muscle cell proliferation closely correlated with MAPK signaling and ERK1/2 in particular (13). For these reasons, we focused on ERK1/2 signaling in this study.

In the present study, we evaluated the effects of ADM and ADT on PASMC proliferation, as well as collagen I, collagen III, and phosphorylated (p)-ERK1/2 expression, to determine if the ERK1/2 signal transduction pathway was activated during the response.

\section{Material and Methods}

\section{Animals and cell culture}

Four-week-old male Wistar rats (body weight: 100$150 \mathrm{~g}, \mathrm{n}=10$ ) were purchased from the Laboratory Animal Center of Medical School, Shandong University. The Shandong University Institutional Animal Care and Use Committee approved animal care and procedures. Animal use was in accordance with National Institutes of Health and institutional guidelines. Animals were killed using intravenous anesthesia. This study was carried out from June 2011 to February 2012.

In this study, we used an adherent tissue explant method for the primary culture of rat PASMCs that is simple and economical. Although this method requires a long culture period, the cells grow well and produce abundant cells after passaging (14). As determined using a mouse monoclonal smooth muscle anti- $\alpha$-actin antibody (Sigma-Aldrich, USA), the purity of the cultured cells approached $87 \%$. Although primary culture of cells from younger rats was often successful, the target cells were difficult to isolate because the vessels were small and thin. Older rats were not suitable for primary culture because of the low viability of their cells. Therefore, we selected healthy 1-month-old male rats, weighing 100$150 \mathrm{~g}$. Since pulmonary vascular remodeling mainly occurs in distal pulmonary arterioles and manifests as smooth muscle cell hyperplasia, medial hypertrophy, and muscularization of pulmonary arterioles with microthrombosis and luminal stenosis, the PASMCs used in the current study were harvested from the distal pulmonary arterioles.

Lungs harvested from animals that had been anesthetized with $2 \%$ pentobarbital were rinsed twice in PBS and then immersed in $75 \%$ ethanol for $3 \mathrm{~min}$. The blood vessels from the lungs were opened lengthwise, and the medial smooth muscle was exposed by removing the intima using tip-curved forceps $(15,16)$. The vascular media was cut into $1-\mathrm{mm}^{3}$ blocks and transferred to 50-mL culture flasks, so that 25-30-tissue blocks were dispersed uniformly on the bottom of each flask. Highglucose (4500 mg/L) DMEM containing 20\% fetal bovine serum was added to the flasks that were placed inverted in an incubator $\left(37^{\circ} \mathrm{C}, 5 \% \mathrm{CO}_{2}-95 \%\right.$ air and controlled humidity) for 3-6 $\mathrm{h}$ and then righted and cultured for 4-7 days. At that time, cell growth was observed using an inverted microscope $(17,18)$.

\section{Immunofluorescent characterization of PASMCs}

The homogeneity of the cultured cells was confirmed by immunofluorescence using a monoclonal antibody against smooth muscle $\alpha$-actin (Sigma-Aldrich). Trypsinized cells from passage four were seeded onto 6 -well plates $\left(20,000\right.$ cells per well) and cultured at $37^{\circ} \mathrm{C}$ in a $5 \% \mathrm{CO}_{2}$ incubator for $24 \mathrm{~h}$, until confluence. The cells were then incubated with a mouse anti- $\alpha$-actin smooth muscle monoclonal antibody $(1: 500)$ for $1 \mathrm{~h}$ at $37^{\circ} \mathrm{C}$ in a humidified chamber. The blank control was incubated with $10 \mathrm{mM}$ PBS. The cells were then incubated for $1 \mathrm{~h}$ at $37^{\circ} \mathrm{C}$ with an FITC-labeled goat anti-mouse lgG antibody (1:500; Abcam, UK). Finally, the cells were counterstained with 4',6-diamidino-2-phenylindole (DAPI) for 1-2 min, sealed with sealing liquid resistant to fluorescence quenching, and then examined under fluorescence microscopy (19).

\section{5-Bromo-2'-deoxyuridine (BrdU) incorporation assay}

Cells were exposed to $1 \mu \mathrm{M}, 0.1 \mu \mathrm{M}$, or $10 \mathrm{nM}$ ADM and/or ADT for $48 \mathrm{~h}$ (9). Unstimulated controls were not exposed to either agent. After $48 \mathrm{~h}$, BrdU was added to a final concentration of $10 \mu \mathrm{M}$, and the cells were incubated for a further $3 \mathrm{~h}$ at $37^{\circ} \mathrm{C}$. Then, the cells were fixed with $4 \%$ formalin and preserved overnight at $4{ }^{\circ} \mathrm{C}$ in a humidified chamber. The cells were subsequently incubated with rabbit anti-BrdU antibody (Abcam) at $4{ }^{\circ} \mathrm{C}$ overnight (20).

\section{Cell growth analysis}

Cells were added to 96-well plates, with 5000 cells per well. Assays were done in quadruplicate. Cell Counting Kit-8 (CCK8; $10 \mu \mathrm{L}$ per $100-\mu \mathrm{L}$ reaction system) was added to each well. After $4 \mathrm{~h}$ in culture, the cells were incubated for $2 \mathrm{~h}$ in $5 \% \mathrm{CO}_{2}$ at $37^{\circ} \mathrm{C}$. Cell proliferation 
was monitored by determining the absorbance at $450 \mathrm{~nm}$ using a GENios Pro fluorescence detector (Tecan, USA). Measurements were recorded every $24 \mathrm{~h}$, beginning at $12 \mathrm{~h}$ after treatment, for a total of $156 \mathrm{~h}$.

\section{Immunofluorescence of collagen I, collagen III, and $\mathrm{p}$-ERK1/2}

Cells were divided into the following treatment groups ( $n=10$ wells): 1) $0.1 \mu \mathrm{M}$ ADM or ADT and rabbit anticollagen I antibody (1:200; Abcam); 2) $0.1 \mu \mathrm{M}$ ADM or ADT and rabbit anti-collagen III antibody (1:100; Abcam); 3) $0.1 \mu \mathrm{M}$ ADM or ADT and rabbit p-ERK antibody $(1: 200)$; 4) $0.1 \mu \mathrm{M}$ ADM or ADT and $10 \mathrm{mM}$ PBS (control). The cells were cultured for $48 \mathrm{~h}$, fixed in $4 \%$ paraformaldehyde, and blocked with goat serum. They were then incubated with the above-mentioned primary antibodies and fixed at $4{ }^{\circ} \mathrm{C}$ in a wet box overnight. Cells incubated with $10 \mathrm{mM}$ PBS served as the control for the antibody staining. Next, the cells were treated with FITClabeled goat anti-rabbit $\lg \mathrm{G}(1: 100)$, incubated at $37^{\circ} \mathrm{C}$ in a wet box for $30 \mathrm{~min}$, and stained in DAPI for 1-2 min. Five visual fields in each slide were randomly selected under a fluorescence microscope $(400 \times$ magnification $)$ $(10,21)$. The images were processed using the Image-Pro Plus 6.0 (Media Cybernetics, USA) Image Processing Software to obtain the absorbance values under the same time of exposure.

\section{Immunoblotting analysis}

Immunoblotting was performed as described previously (22). To identify the intracellular signaling pathways used by ADM and ADT for regulation of proliferation and collagen synthesis of cultured PASMCs, $10 \mu \mathrm{M}$ PD98059, a cell-permeable ERK/MAPK inhibitor, was added to the cultured PASMCs 30 min prior to ADM or ADT treatment. All the procedures were performed on ice or at $4^{\circ} \mathrm{C}$, and all the solutions were precooled. At the regulated time points, cells were harvested (adherent cells were trypsinized), rinsed twice in PBS buffer, transferred to microfuge tubes, and centrifuged at 1000 $g$ for $5 \mathrm{~min}$. After the supernatant was removed, the cell pellet was resuspended in cell lysate buffer, incubated in an ice bath for $40 \mathrm{~min}$, and centrifuged at 18,000 $\mathrm{g}$ for $10 \mathrm{~min}$. The collected supernatant contained the total cell protein.

We separated $20 \mu \mathrm{g}$ total protein by $12 \%$ SDS-PAGE, and then transferred the proteins to a nitrocellulose membrane (Hybond $^{\mathrm{TM}}$, ECLTM, Amersham Pharmacia, UK). After blocking for $2 \mathrm{~h}$ in Tris buffer supplemented with $0.05 \%$ Tween-20 (TBS-T) and $5 \%$ nonfat milk, the membrane was incubated with the corresponding primary antibody (Abcam) at $4^{\circ} \mathrm{C}$ overnight, rinsed in TBS-T three times for $10 \mathrm{~min}$, and then incubated with the secondary antibody (Abcam) at room temperature for $2 \mathrm{~h}$. The membrane was rinsed again in TBS-T three times for $10 \mathrm{~min}$, and visualized using an ECL Chemiluminescence system (Bio-Rad, USA).

\section{Statistical analysis}

Data are reported as means $\pm S D$. Comparison between groups was analyzed using ANOVA, and the Bonferroni test was used when $P<0.05$. Data were processed using the SPSS 15.0 software (SPSS, USA), and $\mathrm{P}<0.05$ was considered to be statistically significant.

\section{Results}

\section{Pulmonary artery smooth muscle cell characterization}

PASMCs were identified as smooth muscle cells by positive staining with mouse anti- $\alpha$-actin antibody and FITC-labeled goat anti-mouse antibody (Figure 1). The cell cytoplasm was stained with FITC, shown in green (Figure $1 \mathrm{~A} 1$ ), and cell nuclei were stained with DAPI, shown in blue (Figure $1 \mathrm{~A} 2$ ). The image in Figure $1 \mathrm{~A} 3$ is Figure 1 A1 merged with Figure 1 A2. The mean homogeneity of the cells approached $87 \%$.

\section{Effect of ADM and ADT on the proliferation of cultured PASMCs}

Both the BrdU incorporation test (Figure 2) and the CCK8 test (Figure 3) showed that ADM, when used at concentrations ranging from $1 \mu \mathrm{M}$ to $10 \mathrm{nM}$, inhibited the proliferation of treated PASMCs, which showed a significant

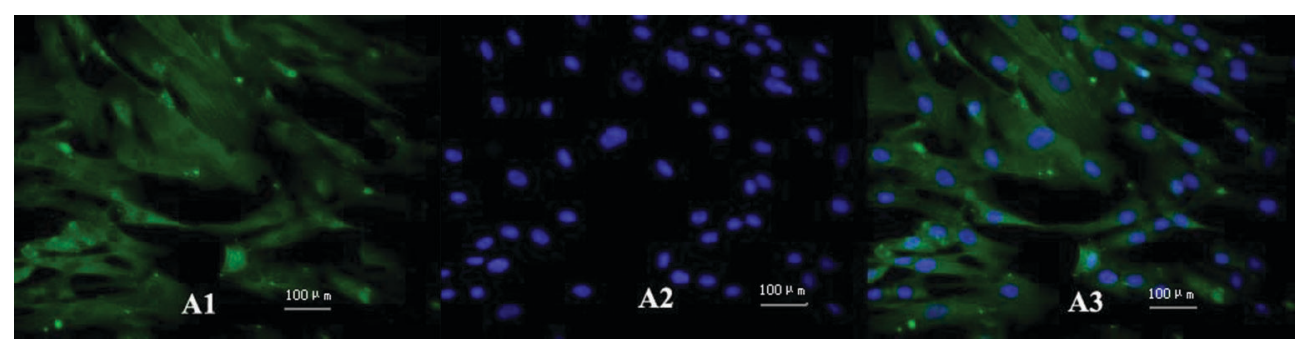

Figure 1. Identification of rat pulmonary arterial smooth muscle cells using a mouse anti-human smooth muscle $\alpha$-actin monoclonal antibody. The images were acquired using an inverted phase contrast microscope (200 $\times$ magnification). A1, The cell cytoplasm was stained with FITC (green). A2, The cell nuclei were stained with DAPI (blue). A3, A1 merged with A2. 


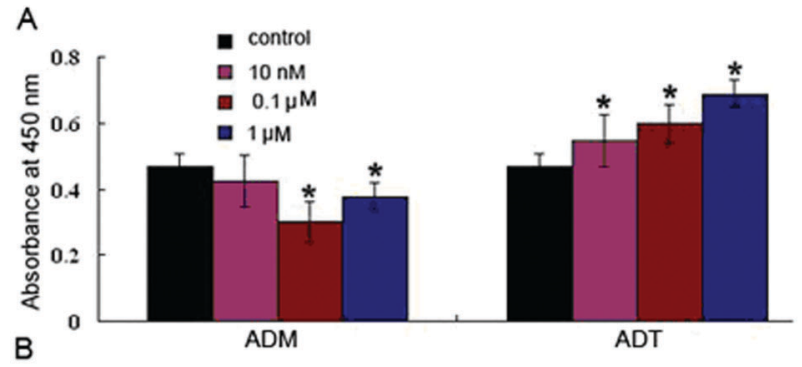

B

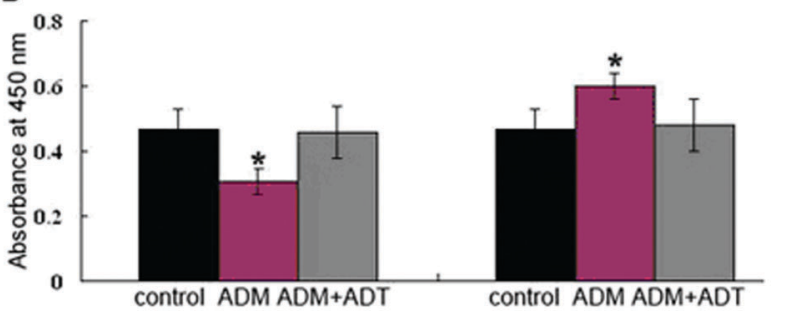

Figure 2. A, Effect of increasing concentrations of ADM or ADT on cell proliferation in cultured PASMCs. Cell proliferation was assayed with BrdU incorporation. Data are reported as mean \pm SE absorbance for $n=6$ rats per group. ${ }^{*} \mathrm{P}<0.05$ vs control (one-way ANOVA). B, Effect of $0.1 \mu \mathrm{M}$ ADM, ADT, or $\mathrm{ADM}+\mathrm{ADT}$ on the cell proliferation of cultured rat PASMCs. Cell proliferation was assayed with BrdU incorporation. PASMCs: pulmonary arterial smooth muscle cells; ADM: adrenomedullin; ADT: adrenotensin. Data are reported as mean $\pm S E$ absorbance for $n=6$ rats per group. ${ }^{*} P<0.05$ vs control (one-way ANOVA).

decrease in proliferation compared to the unstimulated control (BrdU, $\mathrm{P}<0.05$; CCK8, $\mathrm{P}<0.01$ ). In contrast, ADT upregulated proliferation in treated PASMCs at concentrations of $1 \mu \mathrm{M}, 0.1 \mu \mathrm{M}$, and $10 \mathrm{nM}$ (BrdU, $\mathrm{P}<0.01$; CCK8, $\mathrm{P}<0.05)$. Simultaneous addition of $0.1 \mu \mathrm{M}$ ADM and $0.1 \mu \mathrm{M}$ ADT did not affect cell proliferation (no statistical difference compared with the control; $P>0.05$ ), indicating that ADM and ADT exhibit reciprocal inhibition effects on the proliferation of cultured PASMCs.

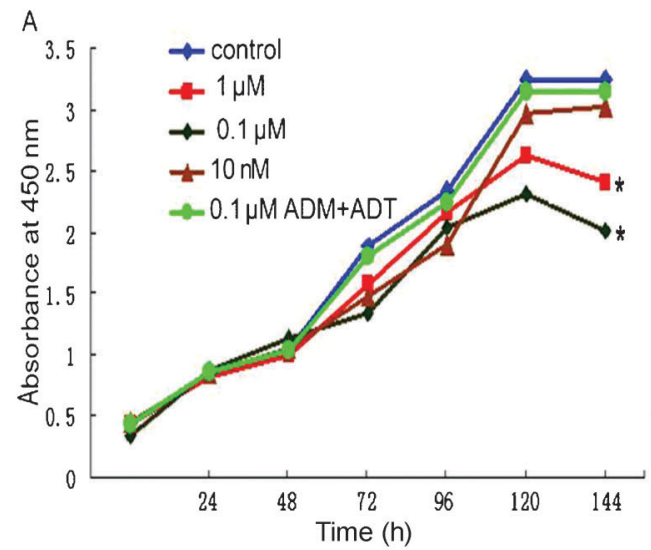

\section{Effect of $0.1 \mu \mathrm{M}$ ADM and $0.1 \mu \mathrm{M}$ ADT on collagen I expression in cultured PASMCs}

The cells in Figure 4(a) A1, treated with ADM and stained for collagen I, show low fluorescence, indicating low collagen I expression; whereas those in Figure 4(a) B1, treated with ADT and also stained for collagen I, show strong fluorescence, indicating high collagen I expression. The cell nuclei for the two groups of cells (Figure 4(a) A2 and 4(a) B2, respectively) are shown with blue fluorescence. The findings indicate that ADM inhibited, whereas ADT upregulated, collagen I expression in cultured PASMCs.

\section{Effect of $0.1 \mu \mathrm{M}$ ADM and $0.1 \mu \mathrm{M}$ ADT on the expression of collagen III in cultured PASMCs}

The cells in Figure 4(b) A1, treated with ADM and stained for collagen III, show low fluorescence, indicating low collagen III expression, whereas those in Figure 4(b) B1, treated with ADT and stained for collagen III, show high fluorescence, indicating high collagen III expression. The cell nuclei in both groups [Figure 4(b) A2 and 4(b) B2] were stained with blue fluorescence. Figure 4(b) $A 3$ and Figure 4(b) B3 are Figure 4(b) A1 merged with Figure 4(b) A2 and Figure 4(b) B1 merged with Figure 4(b) B2, respectively. These findings indicate that $A D M$ inhibited the expression of collagen III in PASMCs, whereas ADT enhanced it.

\section{Effect of $0.1 \mu \mathrm{M}$ ADM and $0.1 \mu \mathrm{M}$ ADT on the expression of $\mathrm{p}-\mathrm{ERK} 1 / 2$ in cultured PASMCs}

The cells in Figure 4(c) A1, treated with ADM and stained for $p$-ERK1/2, show low fluorescence, indicating low p-ERK1/2 expression, whereas those in Figure 4(c) $B 1$, treated with ADT and stained for $p-E R K 1 / 2$, show high fluorescence, indicating high $\mathrm{p}-\mathrm{ERK} 1 / 2$ expression. Figure 4(c) A2 and Figure 4(c) B2 show the nuclei with blue fluorescence. Figure 4(c) A3 and Figure 4(c) B3 are
B

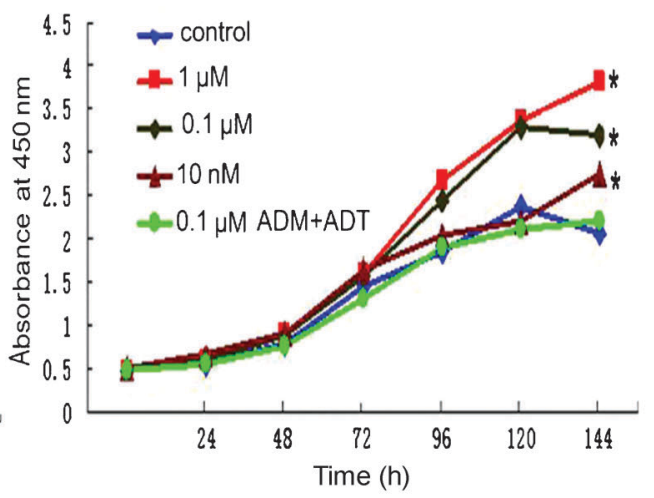

Figure 3. Proliferation curve of cultured PASMCs by the CCK8 test. $A$, Increasing concentrations of ADM or $0.1 \mu M$ ADM + ADT. $B$, Increasing concentrations of ADT or $0.1 \mu \mathrm{M}$ ADM + ADT. PASMCs: pulmonary arterial smooth muscle cells; ADM: adrenomedullin; $A D T$ : adrenotensin. Data are reported as mean $\pm S E$ absorbance for $n=6$ rats per group. ${ }^{*} P<0.05$ vs control (one-way ANOVA). 
a
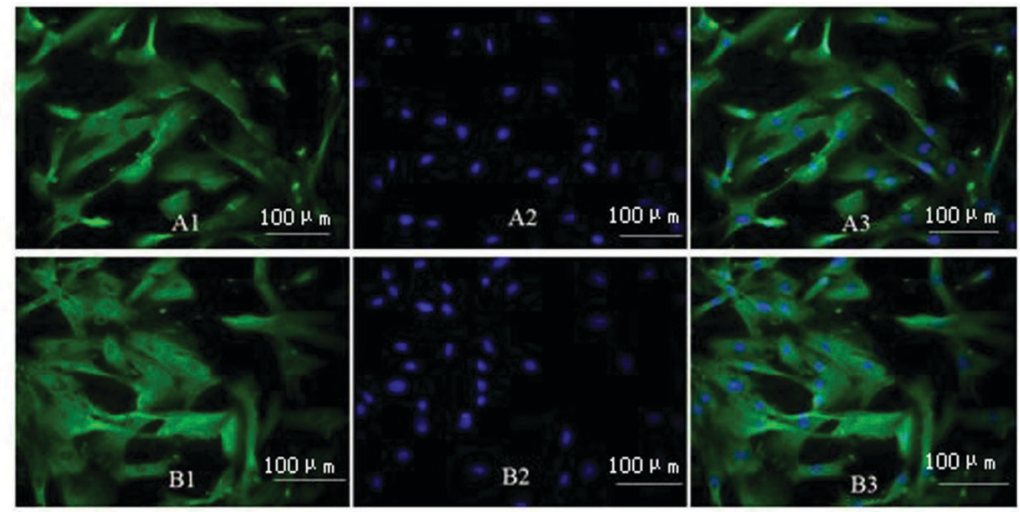

$\mathrm{b}$
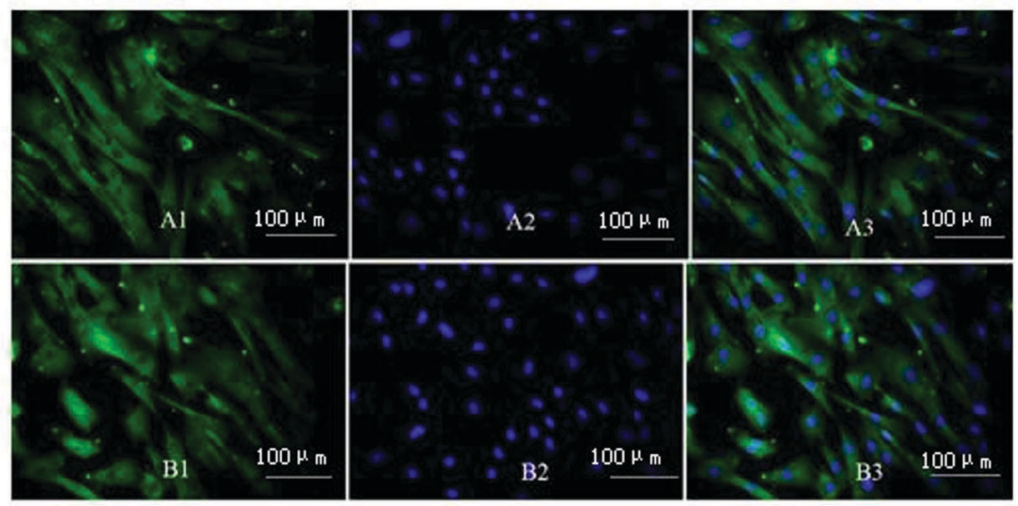

C
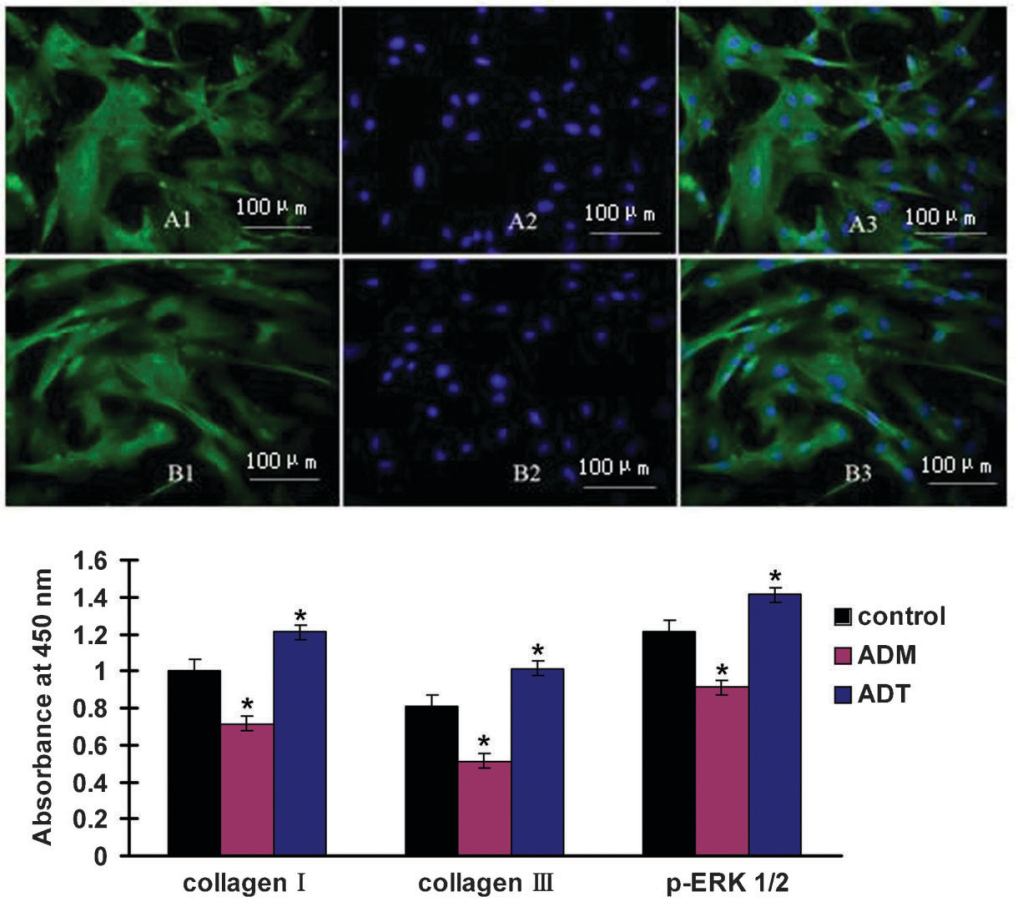

Figure 4. Protein expression of collagen I, collagen III and p-ERK1/2 in cultured PASMCs. Panels $a, b$, and $c$, Influence of $0.1 \mu \mathrm{M}$ ADM (A1-A3) and ADT (B1-B3) on the expression of (a) collagen type I (b) collagen type III and (c) p-ERK1/2 in cultured PASMCs (400 $\times$ magnification). The cell cytoplasm was stained with FITC (green; A1 and B1). The cell nuclei were stained with DAPI (blue; A2 and B2). A 3 and B3 represent the overlapped images of A1 merged with A2 and B1 merged with B2, respectively. Bottom panel, Summary data showed the influence of $0.1 \mu \mathrm{M}$ ADM and ADT on the expression of collagen I, collagen III, and p-ERK1/2 in cultured PASMCs by immunofluorescence. PASMCs: pulmonary arterial smooth muscle cells; ADM: adrenomedullin; ADT: adrenotensin. Data are reported as mean $\pm S E$ absorbance for $n=10$ rats per group. ${ }^{*} \mathrm{P}<0.05$ vs control (one-way ANOVA). 
Figure 4(c) A1 merged with Figure 4(c) A2 and Figure 4(c) B1 merged with Figure 4(c) B2, respectively. These images indicate that ADM inhibited the expression of $p$ ERK1/2 in PASMCs, whereas ADT enhanced it. The
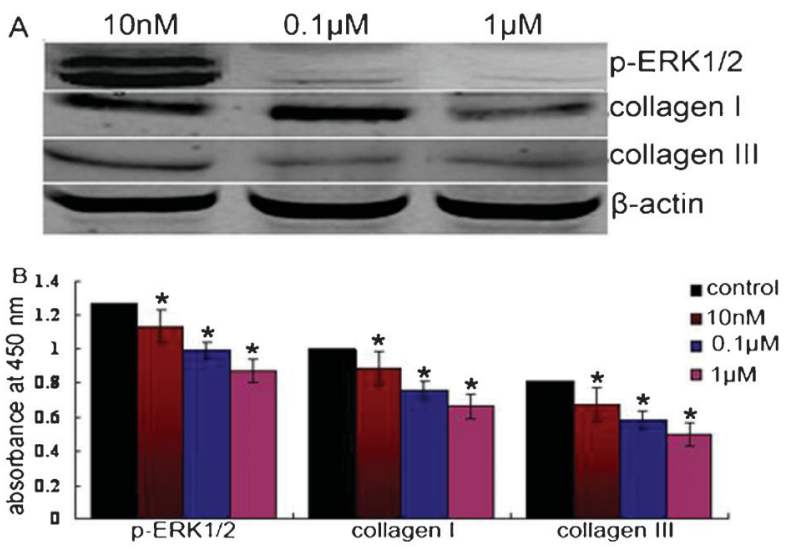

Figure 5. A, Effect of different concentrations of ADM on the protein expression of collagen I, collagen III, and p-ERK1/2 in cultured PASMCs by immunoblotting. $\beta$-actin was used as an internal control. $B$, Effect of stimulation of cultured PASMCs with $10 \mathrm{nM}, 0.1 \mu \mathrm{M}, 1 \mu \mathrm{M}$ ADM on the expression of collagen I, collagen III, and p-ERK1/2. PASMCs: pulmonary arterial smooth muscle cells; ADM: adrenomedullin. Data are reported as mean \pm SE absorbance for $n=6$ rats per group. ${ }^{*} \mathrm{P}<0.05$ vs control (one-way ANOVA).

A

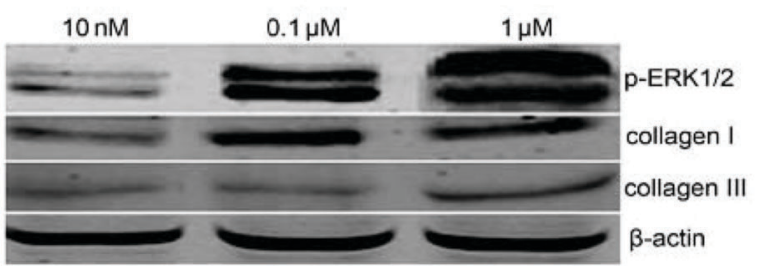

B

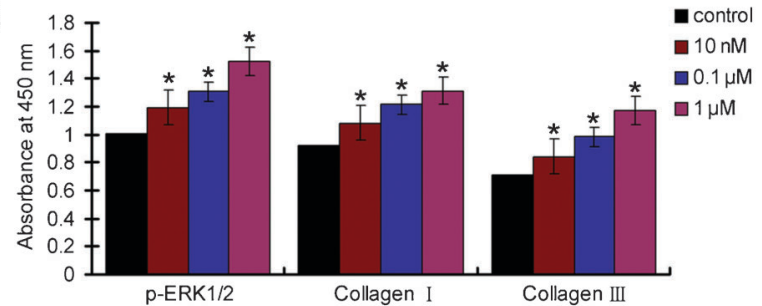

Figure 6. $A$, Effect of different concentrations of ADT on the protein expression of collagen I, collagen III, and p-ERK1/2 in cultured PASMCs by immunoblotting. $\beta$-actin served as an internal control. $B$, Summary data of the influence of $10 \mathrm{nM}$, $0.1 \mu \mathrm{M}$, and $1 \mu \mathrm{M}$ ADT on the expression of collagen I, collagen $\mathrm{III}$, and $\mathrm{p}-\mathrm{ERK} 1 / 2$ in cultured PASMCs. PASMCs: pulmonary arterial smooth muscle cells; ADT: adrenotensin. Data are reported as mean $\pm S E$ absorbance for $n=6$ rats per group. ${ }^{*} \mathrm{P}<0.05$ vs control (one-way ANOVA). primary antibody control showed no staining, indicating that the primary antibody was specific.

Summary analysis of the effects of $0.1 \mu M$ ADM and $0.1 \mu \mathrm{M}$ ADT on the expression of collagen I, collagen III, and $p-E R K 1 / 2$ in cultured rat PASMCs

The absorbance ratio (Figure 4, bottom panel) showed that ADM inhibited the expression of collagens I and III and $p-E R K 1 / 2$ in cultured rat PASMCs $(P<0.01)$, whereas ADT enhanced them $(P<0.05)$.

Effect of ADM and ADT on the expression of collagen I, collagen III, and p-ERK1/2 protein in cultured PASMCs by immunoblotting

Absorbance results showed that ADM inhibited the expression of collagen I and collagen III protein and

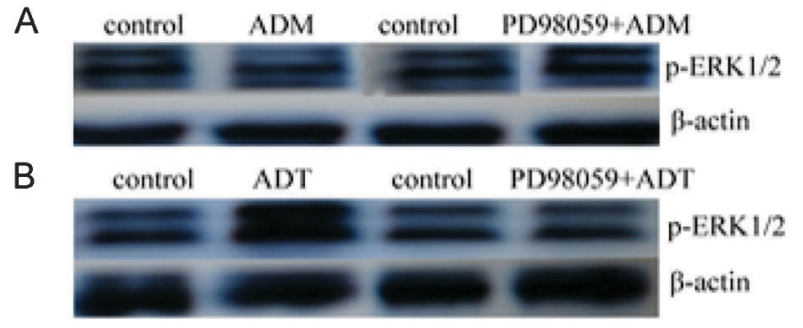

C
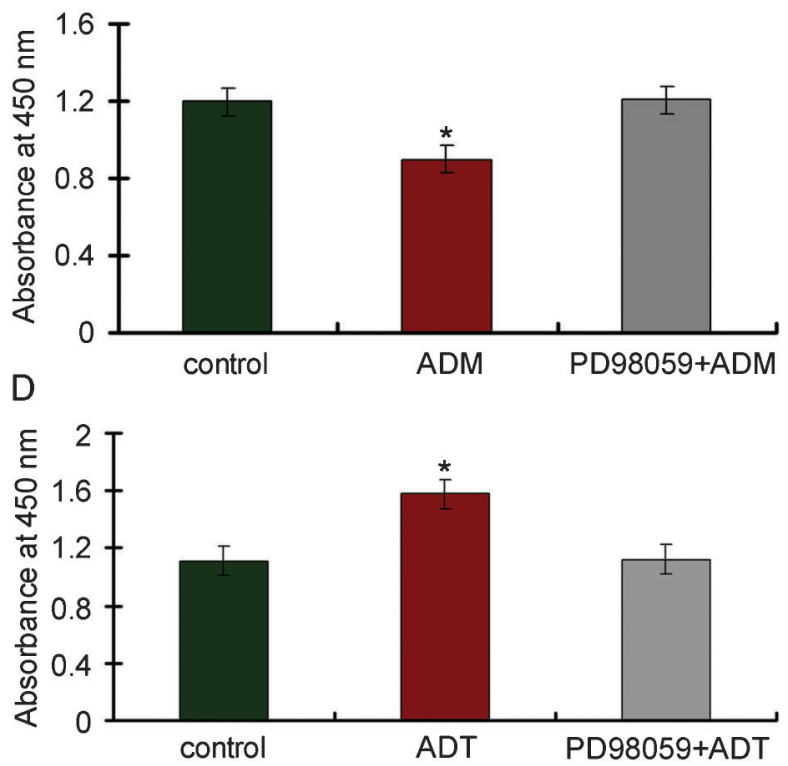

Figure 7. Effect of PD98059 on p-ERK1/2 protein expression of cultured PASMCs stimulated by $(A) 0.1 \mu \mathrm{M}$ ADM or $(B) 0.1 \mu \mathrm{M}$ ADT, shown by immunoblotting. $\beta$-actin served as an internal control. Summary data of the influence of PD98059 on the expression of $p$-ERK1/2 in cultured PASMCs stimulated by $(C)$ $0.1 \mu \mathrm{M}$ ADM or $(D) 0.1 \mu \mathrm{M}$ ADT. PASMCs: pulmonary arterial smooth muscle cells; ADM: adrenomedullin; ADT: adrenotensin. Data are reported as mean \pm SE absorbance for $n=6$ rats per group. ${ }^{*} \mathrm{P}<0.05$ vs control (one-way ANOVA). 
decreased $\mathrm{p}$-ERK1/2 protein in a dose-dependent manner $(\mathrm{P}<0.05, \mathrm{P}<0.05$, and $\mathrm{P}<0.01$, respectively; Figure 5). In contrast, ADT increased protein expression for collagen I, collagen III, and p-ERK1/2 in a dose-dependent manner $(P<0.05, P<0.05$, and $P<0.01$, respectively; Figure 6). These results indicate that the ERK1/2 signaling pathway was activated, concomitant with the increase in proliferation, by ADT stimulation, and that, in contrast, ERK1/2 signaling was inhibited and cell proliferation was decreased by ADM stimulation.

\section{Cellular mechanisms of ADM and ADT on proliferation and collagen synthesis in cultured PASMCs}

Absorbance showed that the cell-permeable ERK/ MAPK inhibitor PD98059 (10 $\mu \mathrm{M})$ significantly inhibited the downregulating effect of $\mathrm{ADM}$ and the upregulating effect of ADT on $p-E R K 1 / 2$ protein expression $(P<0.05$; Figure 7), indicating that ADM and ADT may regulate the proliferation and collagen synthesis of PASMCs through the ERK1/2 signaling pathway.

\section{Discussion}

In the present study, we provide new evidence that ADM and ADT exhibit reciprocal effects on the proliferation of cultured rat PASMCs. ADM exerted an inhibitory effect, and ADT, a stimulatory effect, on the proliferation of cultured rat PASMCs, particularly at a concentration of $0.1 \mu \mathrm{M}$. ADM is a vasoactive polypeptide that functions to dilate blood vessels and inhibit vascular smooth muscle cell proliferation and migration by interacting with specific receptors (23).

As previously reported, ADM and ADT participate in hypoxia-induced pulmonary vascular remodeling $(24,25)$. A recent animal study revealed that ADM could delay and reverse pulmonary vascular remodeling, which suggested an encouraging therapeutic potential (2). It was also demonstrated that inhaled or intravenously administered ADM could decrease the pulmonary blood pressure of patients with pulmonary hypertension and reverse pulmonary vascular hypertrophy (26). These effects indicated the clinical significance of ADM.

In contrast to ADM, ADT induces blood vessel constriction and promotes the proliferation of vascular smooth muscle cells. ADT also stimulates synthesis and secretion of extracellular matrix in cultured rat mesangial cells by interacting with a receptor that has not yet been identified (9). The present study builds on these past reports to extend the functions of ADM and ADT to PASMCs.

The BrdU incorporation test and CCK8 assay both showed that ADM, especially at a concentration of $0.1 \mu \mathrm{M}$, inhibited PASMC proliferation, possibly by inhibiting DNA synthesis and mitosis. It was also shown that ADT stimulated PASMC proliferation in a dose-dependent manner, possibly also through the promotion of DNA synthesis and mitosis. Hypertrophy of the pulmonary vascular wall and luminal stenosis caused by the proliferation of PASMCs is an important influence in development of pulmonary hypertension and pulmonary vascular remodeling (27).

Collagen I and III expression in rat PASMCs decreased after exposure to ADM, but increased after exposure to ADT. ADM may indirectly influence collagen expression by reducing the number of PASMCs by inhibiting cell proliferation. ADT, however, may enhance the mRNA expression of procollagen I and III in PASMCs at the transcription level, which would serve to upregulate the synthesis of collagen I and III proteins (28). Additionally, ADT may impair collagen degradation, thereby increasing the total content of collagen I and III proteins in rat PASMCs. Collagen is a major component of the extracellular matrix; collagen I and III are present in vascular walls. Collagen helps to determine vascular tension resistance and elasticity (29). The accumulation of collagen protein in the vessel wall can increase vessel thickness and stiffness, playing an important role in hypoxia-induced pulmonary vascular remodeling (8). Collagen is located outside the cell, thus the collagen expression seen inside the cell in this study may be newly synthesized collagen that has not yet been excreted.

As previously reported, the addition of ADM to cultured smooth muscle cells could inhibit cell migration, excessive aggregation of microtubules, and excessive stabilization of the cytoskeleton, thus delaying or suppressing hypertrophy, hyperplasia, and migration of smooth muscle cells (30). In addition, ADM can induce smooth muscle cells into hyperpolarization by activating cation channels, causing a decrease in intracellular calcium. ADM can also activate phosphatidylinositol-3 kinase and protein kinase B/Akt, enhancing the activity of endothelial nitric oxide synthase via phosphorylation (31). ADM has also been shown to modify endothelial progenitor cells within the pulmonary tissue of rats with pulmonary hypertension, which could decrease the pulmonary blood pressure markedly and inhibit smooth muscle cell remodeling $(32,33)$.

The present study showed that the expression of p-ERK1/2 in PASMCs changed after exposure to ADM and ADT. The cell-permeable ERK/MAPK inhibitor PD98059 blocked the downregulatory effect of ADM and the upregulatory effect of ADT on the expression of p-ERK1/2, indicating that $A D M$ and $A D T$ regulate the proliferation and collagen synthesis of cultured PASMCs through the ERK1/2 signaling pathway. Activated ERK1/2 can initiate and upregulate the proliferation genes for PASMCs via nuclear translocation, leading to the proliferation of the cells. ADM can also directly inhibit the ERK/MAPK signaling pathway, decreasing production of downstream kinases related to proliferation and secretion 
of extracellular matrix, thus inhibiting cell differentiation and proliferation by suppressing the functionality of transcription factors (32). In contrast, ADT may regulate the ERK/MAPK signaling pathway through a mechanism opposite to that of ADM. Although ADT and ADM are derived from the same precursor, they have opposing biological functions, which are necessary for maintaining stability and equilibrium in the ERK/MAPK signal transduction pathway.

In conclusion, our results indicate that therapeutic agents that enhance ADM activity while inhibiting ADT

\section{References}

1. Rabinovitch M. Molecular pathogenesis of pulmonary arterial hypertension. J Clin Invest 2008; 118: 2372-2379, doi: $10.1172 / \mathrm{JCl} 33452$.

2. Stenmark KR, Rabinovitch M. Emerging therapies for the treatment of pulmonary hypertension. Pediatr Crit Care Med 2010; 11: S85-S90, doi: 10.1097/PCC.0b013e3181c76db3.

3. Lu KK, Trcka D, Bendeck MP. Collagen stimulates discoidin domain receptor 1-mediated migration of smooth muscle cells through Src. Cardiovasc Pathol 2011; 20: 71-76, doi: 10.1016/j.carpath.2009.12.006.

4. Guidolin D, Albertin G, Sorato E, Oselladore B, Mascarin A, Ribatti $D$. Mathematical modeling of the capillary-like pattern generated by adrenomedullin-treated human vascular endothelial cells in vitro. Dev Dyn 2009; 238: 1951-1963, doi: 10.1002/dvdy.22022.

5. Kaafarani I, Fernandez-Sauze S, Berenguer C, Chinot O, Delfino C, Dussert $\mathrm{C}$, et al. Targeting adrenomedullin receptors with systemic delivery of neutralizing antibodies inhibits tumor angiogenesis and suppresses growth of human tumor xenografts in mice. FASEB J 2009; 23: 34243435, doi: 10.1096/fj.08-127852.

6. Cuifen Z, Lijuan W, Li G, Wei X, Zhiyu W, Fuhai L. Changes and distributions of peptides derived from proadrenomedullin in left-to-right shunt pulmonary hypertension of rats. Circ $J$ 2008; 72: 476-481, doi: 10.1253/circj.72.476.

7. Nishikimi T, Karasawa T, Inaba C, Ishimura K, Tadokoro K, Koshikawa S, et al. Effects of long-term intravenous administration of adrenomedullin (AM) plus hANP therapy in acute decompensated heart failure: a pilot study. Circ $J$ 2009; 73: 892-898, doi: 10.1253/circj.CJ-08-0487.

8. Sackett DL, Ozbun L, Zudaire E, Wessner L, Chirgwin JM, Cuttitta $F$, et al. Intracellular proadrenomedullin-derived peptides decorate the microtubules and contribute to cytoskeleton function. Endocrinology 2008; 149: 28882898, doi: 10.1210/en.2007-1763.

9. Xue H, Yuan P, Zhou L, Yao T, Huang Y, Lu LM. Effect of adrenotensin on cell proliferation is mediated by angiotensin II in cultured rat mesangial cells. Acta Pharmacol Sin 2009; 30: 1132-1137, doi: 10.1038/aps.2009.103.

10. Li GW, Xing WJ, Bai SZ, Hao JH, Guo J, Li HZ, et al. The calcium-sensing receptor mediates hypoxia-induced proliferation of rat pulmonary artery smooth muscle cells through MEK1/ERK1,2 and PI3K pathways. Basic Clin Pharmacol Toxicol 2011; 108: 185-193, doi: 10.1111/j.1742-7843.2010. 00639.x. effects may provide a novel strategy for the control of pulmonary vascular remodeling.

\section{Acknowledgments}

Research supported in part by the National Natural Science Foundation (\#30900730), the Shandong Province Foundation for Excellent Young and Midlife Scholars (\#2005BS02003), and the Shandong Province Natural Science Foundation (\#Y2008C44 and \#Q2007D01).

11. Chung HH, Dai ZK, Wu BN, Yeh JL, Chai CY, Chu KS, et al KMUP-1 inhibits pulmonary artery proliferation by targeting serotonin receptors/transporter and NO synthase, inactivating RhoA and suppressing AKT/ERK phosphorylation. Vascul Pharmacol 2010; 53: 239-249, doi: 10.1016/j.vph.2010. 09.003.

12. Jiang J, Wang S, Wang Z, Ma J, Liu S, Li W, et al. The role of ERK1/2 in 15-HETE-inhibited apoptosis in pulmonary arterial smooth muscle cells. J Recept Signal Transduct Res 2011; 31: 45-52, doi: 10.3109/10799893.2010.512013.

13. Zhao CF, Wang LJ, Gao L, Chang P, Xia W, Wang R, et al. [Roles and signal pathways of adrenomedullin and adrenotensin in pulmonary remodeling due to left to right shunt in rats]. Zhonghua Er Ke Za Zhi 2008; 46: 585-590.

14. Farah OR, Li D, Mclntyre BA, Pan J, Belik J. Airway epithelial-derived factor relaxes pulmonary vascular smooth muscle. Am J Physiol Lung Cell Mol Physiol 2009; 296: L115-L120, doi: 10.1152/ajplung.90391.2008.

15. Peng G, Wang J, Lu W, Ran P. Isolation and primary culture of rat distal pulmonary venous smooth muscle cells Hypertens Res 2010; 33: 308-313, doi: 10.1038/hr.2009.234.

16. Moreno L, Perez-Vizcaino F, Harrington L, Faro R, Sturton G, Barnes PJ, et al. Pharmacology of airways and vessels in lung slices in situ: role of endogenous dilator hormones. Respir Res 2006; 7: 111, doi: 10.1186/1465-9921-7-111.

17. Belik J, Stevens D, Pan J, Mclntyre BA, Kantores C, Ivanovska J, et al. Pulmonary vascular and cardiac effects of peroxynitrite decomposition in newborn rats. Free Radic Biol Med 2010; 49: 1306-1314, doi: 10.1016/j.freeradbiomed. 2010.07.021.

18. Manoury B, Etheridge SL, Reid J, Gurney AM. Organ culture mimics the effects of hypoxia on membrane potential, $\mathrm{K}^{+}$) channels and vessel tone in pulmonary artery. Br J Pharmacol 2009; 158: 848-861, doi: 10.1111/j. 1476-5381.2009.00353.x

19. Ochoa CD, Baker H, Hasak S, Matyal R, Salam A, Hales $\mathrm{CA}$, et al. Cyclic stretch affects pulmonary endothelial cell control of pulmonary smooth muscle cell growth. Am J Respir Cell Mol Biol 2008; 39: 105-112, doi: 10.1165/rcmb.2007$02830 \mathrm{C}$.

20. Wu D, Doods H, Stassen JM. Inhibition of human pulmonary artery smooth muscle cell proliferation and migration by sabiporide, a new specific NHE-1 inhibitor. J Cardiovasc Pharmacol 2006; 48: 34-40, doi: 10.1097/01.fjc.0000239691. 69346.6a. 
21. Zhao Q, Liu Z, Wang Z, Yang C, Liu J, Lu J. Effect of preprocalcitonin gene-related peptide-expressing endothelial progenitor cells on pulmonary hypertension. Ann Thorac Surg 2007; 84: 544-552, doi: 10.1016/j.athoracsur.2007. 03.067.

22. Yamanaka R, Otsuka F, Nakamura K, Yamashita M, Otani $\mathrm{H}$, Takeda M, et al. Involvement of the bone morphogenetic protein system in endothelin- and aldosterone-induced cell proliferation of pulmonary arterial smooth muscle cells isolated from human patients with pulmonary arterial hypertension. Hypertens Res 2010; 33: 435-445, doi: 10.1038/hr.2010.16.

23. Ah Kioon MD, Asensio C, Ea HK, Uzan B, Cohen-Solal M, Liote F. Adrenomedullin increases fibroblast-like synoviocyte adhesion to extracellular matrix proteins by upregulating integrin activation. Arthritis Res Ther 2010; 12: R190, doi: $10.1186 / \operatorname{ar} 3160$.

24. Qi JG, Ding YG, Tang CS, Du JB. Chronic administration of adrenomedullin attenuates hypoxic pulmonary vascular structural remodeling and inhibits proadrenomedullin $\mathrm{N}$ terminal 20-peptide production in rats. Peptides 2007; 28: 910-919, doi: 10.1016/j.peptides.2006.12.008.

25. Gonzalez-Rey E, Chorny A, O'Valle F, Delgado M. Adrenomedullin protects from experimental arthritis by down-regulating inflammation and Th1 response and inducing regulatory T cells. Am J Pathol 2007; 170: 263-271, doi: 10.2353/ajpath.2007.060596.

26. Nagaya N, Kyotani S, Uematsu M, Ueno K, Oya H, Nakanishi $\mathrm{N}$, et al. Effects of adrenomedullin inhalation on hemodynamics and exercise capacity in patients with idiopathic pulmonary arterial hypertension. Circulation 2004; 109: 351-356, doi: 10.1161/01.CIR.0000109493. 05849.14

27. Belmadani S, Zerfaoui M, Boulares HA, Palen DI, Matrougui
K. Microvessel vascular smooth muscle cells contribute to collagen type I deposition through ERK1/2 MAP kinase, alphavbeta3-integrin, and TGF-beta1 in response to ANG II and high glucose. Am J Physiol Heart Circ Physiol 2008; 295: H69-H76, doi: 10.1152/ajpheart.00341.2008.

28. Qi JG, Xing CQ, Ding YG, Du JB. [Adrenomedullin alleviates collagen accumulation in pulmonary arteries of rats with hypoxic pulmonary hypertension]. Zhongguo Dang Dai Er Ke Za Zhi 2012; 14: 54-58.

29. Dewachter L, Dewachter C, Naeije R. New therapies for pulmonary arterial hypertension: an update on current bench to bedside translation. Expert Opin Investig Drugs 2010; 19: 469-488, doi: 10.1517/13543781003727099.

30. Ooi CY, Wang Z, Tabima DM, Eickhoff JC, Chesler NC. The role of collagen in extralobar pulmonary artery stiffening in response to hypoxia-induced pulmonary hypertension. Am J Physiol Heart Circ Physiol 2010; 299: H1823-H1831, doi: 10.1152/ajpheart.00493.2009.

31. Murakami S, Kimura H, Kangawa K, Nagaya N. Physiological significance and therapeutic potential of adrenomedullin in pulmonary hypertension. Cardiovasc Hematol Disord Drug Targets 2006; 6: 125-132, doi: 10. 2174/187152906777441867.

32. Zhao YD, Courtman DW, Deng Y, Kugathasan L, Zhang Q, Stewart DJ. Rescue of monocrotaline-induced pulmonary arterial hypertension using bone marrow-derived endothelial-like progenitor cells: efficacy of combined cell and eNOS gene therapy in established disease. Circ Res 2005; 96: 442-450, doi: 10.1161/01.RES.0000157672.70560.7b.

33. Hosoda $T$, Zheng H, Cabral-da-Silva M, Sanada F, IdeIwata N, Ogorek B, et al. Human cardiac stem cell differentiation is regulated by a mircrine mechanism. Circulation 2011; 123: 1287-1296, doi: 10.1161/CIRCULATIONAHA.110. 982918. 